\title{
Análise do conto "Impacto Poético", de Luiz Silva, sob a ótica da experiência no Movimento Negro
}

\section{Analysis of "Impacto poético" by Luiz Silva, from the perspective of the experience in the Black Movement}

Anderson Caetano dos Santos ${ }^{1}$

\section{RESUMO}

Este trabalho toma o gênero conto como referência para estudar a produção narrativa de Cuti, Luiz Silva, escritor contemporâneo, que se dedica à temática afro-brasileira, à inserção do negro na sociedade brasileira, à experiência desse grupo, às suas vicissitudes, à dualidade de aceitar a condição social imposta por anos de apagamento/silenciamento ou de empreender a participação em movimento de resistência.

PALAVRAS-CHAVE: Experiência; Movimento negro; Luiz Silva; “Impacto poético”.

\section{ABSTRACT}

This work takes the short story as a reference to study the narrative production of Cuti, Luiz Silva, contemporary writer, who is dedicated to the Afro-Brazilian theme, to the insertion of the black in Brazilian society, to the experience of this group, its vicissitudes, duality in accepting the social condition imposed by years of erasure / silencing or engaging in resistance movement.

KEYWORDS: Experience; Black movement; Luiz Silva; “Impacto poético”.

\footnotetext{
${ }^{1}$ Mestrando em Letras, com a pesquisa O Movimento Negro na obra de Luiz Silva (Cuti) e as questões afro-brasileiras.
} 


\section{Introduçāo}

A história e a literatura dos negros no Brasil remetem, comumente, às origens do país como nação colonizada, escravocrata e formada socialmente a partir da pluralidade cultural. Compreender esse cenário histórico e literário significa ir além dos estereótipos difundidos no senso comum brasileiro. A presença dos negros na nossa constituição enquanto nação e as suas múltiplas relações com a sociedade configuram-se como importantes temas de investigação de teorização ao longo da História do Brasil.

Durante séculos, a perversidade escravocrata materializou-se na diferença impressa pela cor da pele e outros sinais do corpo, utilizados como argumento justificador da colonização, encobrindo a exploração econômica, política e social. A questão das relações étnico-raciais, no Brasil, se manifesta nos processos de exclusão, de desigualdades sociais, de preconceitos de um grupo detentor de privilégios sobre a maioria afro-brasileira explorada primeiramente pelo sistema escravagista e, em um segundo momento, pelo sistema capitalista.

A história do Brasil é uma versão concebida por brancos, para os brancos e pelos brancos, exatamente como toda a sua estrutura econômica, sócio-cultural, política e militar tem sido usurpada da maioria da população para o benefício exclusivo de uma elite branca/brancóide, supostamente de origem ário-européia. (NASCIMENTO, 1980, p. 15)

Abdias do Nascimento evidencia que o afro-brasileiro foi escravizado por um sistema que o usou como objeto para construir a nação brasileira. Dessa forma, os afro-brasileiros têm sido privados de um bom nível de escolaridade, de saúde pública de qualidade, de empregos de níveis superiores, dado que, isso tem dificultado em muito a sua ascensão social. Alguns tópicos significativos apontados por Abdias do Nascimento são: o negro visto como trabalhador e produtor da riqueza material do Brasil e, produtor/construtor de uma cultura original. 
Em Literatura e sociedade (2006), de Antonio Candido, destaca-se através de ensaios questões primordiais para o entendimento de uma obra literária. Um desses traços é a vinculação do escritor com o pano de fundo social para a elaboração da obra, bem como o entendimento do leitor dessas características para a realização da crítica literária.

Elas não podem ser entendidas mediante a aplicação pura e simples dos métodos a que ele está habituado, e que supõem na obra uma relativa autonomia, pois, mesmo quando transcritos, não são textos, decifráveis diretamente. Não podem ser desligadas do contexto, isto é, da pessoa que as interpreta, do ato de interpretar e, sobretudo, da situação de vida e de convivência, em função das quais foram elaboradas e são executadas. (CANDIDO, 2006, p. 58)

A compreensão de um momento histórico é a chave para o entendimento de uma obra literária. Os costumes, as tradições e o movimento literário em que o escritor está inserido contribuem para a temática escolhida, bem como a representação dos personagens inseridos na diegese do texto. Desse modo, a indissociabilidade entre literatura e história realiza-se sobre um tripé: momento histórico, estilística literária e o leitor. Este último decodifica o texto a partir da cosmovisão e leituras e/ou contatos anteriores com diversos gêneros textuais existentes.

Para o propósito deste artigo, escolheu-se um conto da obra de Cuti, pseudônimo de Luiz Silva. Ele, nascido na década de 50 em Ourinhos, cidade do interior de São Paulo, é poeta, ficcionista, dramaturgo, crítico literário, ensaísta, contista e romancista. As produções literárias de Cuti no âmbito dos contos são marcadas, em grande medida, pela afirmação de uma consciência étnica afrodescendente, a qual trabalha prioritariamente os problemas que envolvem os negros. Dessa maneira, o que interessa neste estudo, por se tratar de um dado recorrente, é a faceta empenhada e circunscrita em um engajamento literário. Cuti escreve num momento de profunda discussão sobre a produção cultural, bem 
como sobre as representações literárias e históricas de brasileiros afrodescendentes, sobretudo nos movimentos e nas organizações negras.

O conto "Impacto poético" faz parte do livro Quizila, de 1987. Nesta obra destaca-se a temática trazida por protagonistas e demais personagens afro-brasileiros que costumam povoar as novas produções literárias em que se toma o meio afrodescendente como foco. A publicação do livro aconteceu em um momento de reabertura política no Brasil, durante o governo de José Sarney (1985-1990): às vésperas dos cem anos da Abolição da Escravatura no território brasileiro e no mesmo ano da Assembleia Nacional Constituinte. Naquele período, os assuntos pertinentes aos afro-brasileiros eram debatidos, em sua maioria, em agremiações ligadas ao Movimento Negro.

\section{A experiência}

Em linguagem corrente, experiência, enquanto ato ou efeito de experimentar, significa prática de vida indicando o fato de suportar ou sofrer algo, como quando se diz que se experimenta um sentimento ou uma sensação. Por outro lado, experiência é um indicador de competência social ou técnica, no sentido de se possuir habilidade, perícia ou prática, adquiridas com o exercício constante de uma profissão, uma arte ou um ofício. Quem tem acumulado experiências possui algo que Ihe confere autoridade, evidenciando uma distância que separa a ingenuidade juvenil do conhecimento acerca da vida característica do ancião.

Em Teses sobre o conceito de História (1940), Walter Benjamin estabelece uma relação entre o progresso, as imagens e as vozes oprimidas pelas lutas de classes. Torna-se perceptível a preocupação de Benjamin com a maneira como os fatos têm sido contados ao longo da história. No modelo visado pelo pensador, destaca-se a visão dos vencedores como um trunfo. Na contramão de tal modelo, 
Walter Benjamin sugere buscar-se o passado por meio de uma imagem dialética, tornando-se possível compreender de outra forma determinado momento histórico. Essa visão pede que, no processo de olhar para o passado, não se perca de vista as pessoas que a própria história tratou de esquecer - ou talvez nunca tenha se lembrado - ao longo do tempo.

Os derrotados, mulheres e homens, tiveram suas vozes caladas pelos vencedores da História. Assim, constrói-se uma narrativa histórica hegemônica, a narrativa dos vitoriosos. No entanto, apesar de vencidas, essas pessoas deixaram a sua marca no tempo, viveram experiências autênticas, conceberam, ou, pelo menos, viveram, as suas próprias narrativas e, assim, fizeram a História. Na tese de número seis, Walter Benjamin aponta que

Articular historicamente o passado não significa conhecê-lo "como ele de fato foi". Significa apropriar-se de uma reminiscência, tal como ela relampeja no momento de um perigo. Cabe ao materialismo histórico fixar uma imagem do passado, como ela se apresenta, no momento do perigo, ao sujeito histórico, sem que ele tenha consciência disso. O perigo ameaça tanto a existência da tradição como os que a recebem. Para ambos, o perigo é o mesmo: entregar-se às classes dominantes, como seu instrumento. Em cada época, é preciso arrancar a tradição ao conformismo, que quer apoderar-se dela. (BENJAMIN, 1987, p. 224)

Na tese de número sete, o autor completa:

A natureza dessa tristeza se tornará mais clara se nos perguntarmos com quem o investigador historicista estabelece uma relação de empatia. A resposta é inequívoca: com o vencedor. Ora, os que num momento dado dominam são os herdeiros de todos os que venceram antes. A empatia com o vencedor beneficia sempre, portanto, esses dominadores. Isso diz tudo para o materialismo histórico. Todos os que até hoje venceram participam do cortejo triunfal, em que os dominadores de hoje espezinham os corpos dos que estão prostrados no chão. Os despojos são carregados no cortejo, como de praxe. Esses despojos são o que chamamos bens culturais. (BENJAMIN, 1987, p. 225) 
Assim, o fato de a História ser escrita pelos vencedores não significa que inexistam outros escritores dela, mas que estes e suas memórias precisam ser resgatados por gerações do presente e do futuro. Não haveria, por assim dizer, uma História, mas muitas delas. O problema estaria justamente em recuperá-las, dada a avassaladora força da história dos triunfadores, que não é outra senão a oficial. Desse modo, o conto aqui analisado possui o intuito de resgatar essas "outras histórias experimentadas", vividas ao longo do tempo, que têm sido renegadas ou silenciadas pela História brasileira.

\section{0 conto "Impacto Poético"}

Nesse conto², apresentam-se as tensões vividas entre Ildebrando Camargo, Foluke Nguchi e demais personagens secundários num evento artístico ocorrido no "Centro de Negritude Paulistana", sendo estas relatadas por um narrador em terceira pessoa que detém a onisciência dos fatos. No encontro, os atritos, as contradições e as brigas desses personagens destacam a diversidade ideológica de militantes negros. Em "Impacto Poético", escritores e artistas negros preocupam-se em divulgar os trabalhos oriundos de uma perspectiva afro-brasileira.

No sarau ocorrido no "Centro da Negritude Paulistana", destaca-se que a arte negra é feita por afro-brasileiros que concebem sua própria visão de mundo. Os saraus são capazes de alimentar o sentimento de identidade da sociedade e de despertar ao sujeito, através da literatura, novas interpretações sobre os problemas e as necessidades sociais. No encontro, oportuniza-se um espaço para exposição dos trabalhos, para dar voz aos integrantes de um grupo minoritário, bem como propiciar a discussão da temática da negritude. Na noite em que, no conto, desenrola-se a ação, a narrativa situa-se em dois momentos: um do encontro entre os ativistas e outro, nas ruas próximas ao evento artístico, após o

2 Publicado pela primeira vez na sexta edição dos Cadernos Negros, em 1983. 
término do sarau literário, devido à confusão gerada entre os participantes deste evento.

O sarau é uma reunião de pessoas que têm algum vínculo com a arte e a cultura de determinado grupo que compartilha ali as suas obras, reflexões, ideologias. De forma geral, o sarau é uma criação social; um espaço onde pessoas podem expressar aquilo que produzem, ainda que não tenham renome no âmbito da arte. Além disso, é um local em que, de maneira informal, transmite-se conhecimento e, assim, auxilia no processo de construção epistemológica de seus participantes. Em termos de inspiração, o sarau pode exercer grande influência ao motivar as pessoas a criarem ou expressarem algum tipo de arte.

Antes da análise mais detida do conto, é válido apresentar Ildebrando Camargo e Foluke Nguchi, os principais personagens da narrativa, que desenvolvem uma relação de certa oposição no tocante ao fazer literário. Ildebrando Camargo mente no número de livros escritos e vendidos, sendo que se autodenomina um dos maiores intelectuais da cultura negra e poeta da negritude. Além disso, ele tenta construir uma imagem com o intuito de impressionar as pessoas. O protagonista é produtor de diversos gêneros literários, algo que "dizia sempre que tinha uma brecha em qualquer conversa com estranhos." (CUTI, 1987, p. 15). Ele considera-se pesquisador e entendedor da cultura afro-brasileira, sendo que possui as características de uma pessoa arrogante, mentiroso, prepotente, egocêntrico e mulherengo, conforme é possível inferir-se pela leitura do conto.

Aumentava sensivelmente $\mathrm{o}$ número de livros escritos e a quantidade comercializada. Quando o interlocutor era também do ofício, procurava dirigir a conversa para um ponto em que a prepotência cedia um palminho à solidariedade (...). (CUTI, 1987, p. 15)

Ele desempenha outras atividades, tais como escultor, pintor e autor de $A$ Garganta do Ébano (não se menciona a que gênero literário pertenceria tal obra), livro que tem uma edição de dez mil exemplares vendidos. Cumpre, nesse ponto, 
observar que, conforme Houaiss (2001, p. 1429), o termo "garganta", em sentido informal, assume o significado de bravata, mentira - dado que poderia conferir certa ironia posta pelo narrador em relação ao trabalho desenvolvido por Ildebrando Camargo.

O espaço ficcional do conto comporta a presença de outro conhecedor da cultura negra: Foluke Nguchi (pseudônimo de Paulo Xavier). Ele está na faixa dos 30 anos de idade, apresenta estatura mediana, ama a poesia, é invejoso e possui formação universitária. A referência ao diploma universitário indica uma parcela reduzida de afro-brasileiros, visto que as políticas de inclusão social e/ou afirmativas ainda não existiam na década de 1980 no Brasil. Desse modo, esse escritor possui as características de um intelectual ativista e acadêmico, sendo que utiliza a formação universitária para inflar o seu ego, com o intuito de deslegitimar os discursos dos outros personagens.

Se lá estivesse, ah, discorreria sem dúvida sobre coisas verdadeiramente importantes para a poesia negra. Falaria da profundidade do ser-negro-no-mundo e da luta com a palavra. Aquele tal Ildebrando não era um autêntico poeta. Seus versos prosaicos não feriam um milímetro sequer o status quo racista... (CUTI, 1987, p. 16)

No momento do sarau literário, são apresentados os personagens secundários, muitos dos quais sem nome referido, tais como: Marisa Molina (a atriz de teatro apelidada de Marisa Cheguei), Gilmar Rodrigues, uma mulher com cabelo rastafári, um bailarino, um professor de Física, um coordenador dos trabalhos, um homem branco, um crítico literário nordestino e mulato, um jovem militante vinculado ao Movimento Negro Justificado, dois irmãos, um jornalista freelancer, um bailarino careca e a esposa de Ildebrando Camargo.

Nesta análise, três temas recebem destaque: as produções literária e artística oriundas do ponto de vista do negro; os atritos ideológicos entre Ildebrando Camargo e Foluke Nguchi, bem como entre os personagens 
secundários situados no encontro artístico do "Centro da Negritude Paulistana" e após o sarau no centro de militância; e, por último, os estereótipos de desordeiros e/ou bandidos associados aos afro-brasileiros.

O primeiro desses temas indica que a literatura afro-brasileira tem estado em situação de marginalidade devido à falta de estímulos editoriais e/ou pelo engavetamento desse corpus literário. A não publicação de textos com a temática afro-brasileira diminui existência de personagens negros. Desse modo, os leitores tanto brancos quanto negros - não teriam acesso a um material que trabalhe essa temática, o que contribuiria para a manutenção de estereótipos em relação aos afro-brasileiros.

No caso da literatura, essa produção sofre, ao longo do tempo, impedimentos vários à sua divulgação, a começar pela própria materialização em livro. Quando não ficou inédita ou se perdeu nas prateleiras dos arquivos, circulou muitas vezes de forma restrita, em pequenas edições ou suportes alternativos. (DUARTE, 2007, p. 1-2)

A respeito desse tema, vale destacar que o sistema editorial brasileiro tem dificultado a divulgação de uma literatura negra, bem como de uma expressão artística afro-brasileira. Os livros, devido aos altos custos editoriais, são caros e apenas uma pequena parcela dos escritores tem recursos suficientes para lançá-los com regularidade. Nesse contexto, os escritores e artistas afro-brasileiros, em sua maioria, autofinanciam as edições dos livros ou, simplesmente, ficam impedidos de divulgar aquilo que produzem.

Abdias do Nascimento com o Teatro Experimental do Negro (TEN) e o Jornal Quilombo: vida, problemas e aspirações do negro divulgou trabalhos oriundos da perspectiva de afro-brasileiros. O Sarau Afro Mix, produzido pelos Cadernos Negros desde a década de 1970, e o Sarau da Cooperifa, organizado por Sérgio Vaz, são exemplos de ações que se contrapõem ao sistema editorial institucionalizado, segundo Edimilson de Almeida Pereira (2008). A distribuição de folhetos realizada de "mão em mão" denota a situação de marginalidade dessa literatura, pois se 
busca meios para divulgação do material, seja em saraus, encontros literários ou mesmo a venda na rua.

Além disso, este conto também apresenta uma querela entre os personagens centrais. Foluke Nguchi critica Ildebrando porque ele é arrogante e menospreza a capacidade intelectual das pessoas. Além disso, a qualidade dos poemas de Ildebrando não tem impacto na cultura negra devido à falta de autenticidade. Esse atrito entre as personagens revela duas visões antagônicas do fazer literário: 1) Ildebrando preocupa-se com a abordagem dos problemas sociais por meio da arte e procura fazer dela um caminho para a conscientização, sendo ela vista como uma forma de empoderamento de populações socialmente vulneráveis, o que gera, consequentemente, a melhoria da qualidade de vida de tais populações; 2) Foluke Nguchi, por sua vez, defende a ideia da literatura como "arte pela arte", definida pela autonomia e imanência, com o respectivo desligamento de razões pedagógicas externas e privilegiando os aspectos estéticos.

Os desacordos ideológicos ocorrem majoritariamente entre Ildebrando Camargo e Foluke Nguchi, porém os personagens secundários, alguns dos quais também podem ser considerados arrogantes e vaidosos, divergem das opiniões dos principais e entre si.

- É cinquenta cruzeiros só - um poeta baixinho vendia na platéia poemas ilustrados.

- São cinco poemas mais o desenho, né moça!? - insistia ele. Ildebrando no palco, irritado com a concorrência, não perdoou aquela intromissão em voz alta:

- Ô, minha gente! Gostaria de pedir silêncio na assistência. Se é pra ser interrompido, eu retiro meu discurso.

- Ô, cara, vai vender poesia lá fora, pô! - gritou alguém em tom irritadiço para Gilmar Rodrigues que não gostou nada da advertência e retrucou, firmando o boné na cabeça:

- Não te conheço rapaz não, rapaz. Vendo aonde eu quero.

- Mas não vê que tá atrapalhando? - berrou a jovem de cabelos caindo em tranças de lã, excessivamente feminina. Comoção profunda no peito de Ildebrando. O pavio de simpatia e desejo que nutria por aquela mulher de agressividade tão exposta, meiga no entanto, teve ímpeto de faiscar paixão. Era a princesa de suas 
fantasias, tentativa frustrada de aproximação, coração escorregando naquelas curvas... Assim, logo que o poeta vendedor deu o troco:

- Olha aqui, rastafári, não grita comigo não! Ildebrando interveio:

- A moça tem mais é que gritar mesmo, meu amigo! Estamos numa reunião artística e não em supermercado! (CUTI, 1987, p. 16-7)

O longo excerto exibe uma discussão entre uma mulher de cabelo rastafári, um militante do Movimento Negro Justificado e os poetas Gilmar Rodrigues e Ildebrando Camargo. Dessa forma, a existência de personagens com cosmovisões diferentes favorece o surgimento de conflitos ideológicos. No ambiente da militância, essas pessoas estão preocupadas em discutir sobre a cultura afro-brasileira e em divulgar os seus trabalhos artísticos. Sendo assim, os desejos individuais sobressaem-se ao ideal do ativismo negro e da luta antirracista.

Além disso, o conto explora os estereótipos negativos associados aos afro-brasileiros, como a desordem e o banditismo, sendo este último uma fonte de conflito e desconforto muito comum aos negros, já que evoca a iminência de ser preso injustamente ou morto.

Ildebrando, sem um minuto para pensar naquela situação de intimidade súbita, caminhava por luares românticos, preparando uma declaração plausível. Passou uma perua da polícia, e ele que sempre pensava nos documentos naqueles momentos, nem sequer reparou. (CUTI, 1987, p. 19-20)

A violência policial não é esporádica, eventual, nem local (tem dimensão nacional), mas tem direção certa. As vítimas da truculência da polícia são, via de regra, jovens negros, pobres e moradores de áreas de baixo acesso a políticas públicas. Portanto, a violência policial é um comportamento pautado por uma lógica institucional que efetivamente instiga e produz mais violência.

Desse modo, a vinculação do negro a características negativas tem se perpetuado na sociedade brasileira, pretensamente atribuindo traços que dificultam, dentre outros aspectos, a ascensão econômica dos afro-brasileiros. Essa 
é uma situação que atinge a maioria dos negros brasileiros, sendo que essa perspectiva reduz as possibilidades de integração na ordem competitiva capitalista e na sociedade de classes.

O título do conto - Impacto poético - alude ao choque discursivo da literatura, com formas diferentes de se produzir uma arte afro-brasileira de acordo com perspectivas de personagens distintos. Esse impacto refere-se ainda às divergências ideológicas nas relações humanas entre negros e brancos, e mesmo entre negros e negros. Ainda que parte do mesmo grupo racial, Ildebrando, Foluke e os outros artistas são escritores e artistas com posicionamentos diferentes sobre o fazer artístico-literário.

\section{Consideraçōes finais}

A partir do conto analisado torna-se evidente a preocupação de Cuti com a temática da identidade negra na sociedade brasileira. Por meio de um histórico de militância do próprio escritor, que desencadeou em uma sólida formação acadêmica, nota-se que esse intelectual principiou com a temática de formação de associações de movimento social negro expresso em seu primeiro livro de contos, Quizila. Esse caráter de contestação reflete o contexto brasileiro, onde as organizações sociais e o surgimento de partidos políticos afloraram no processo de redemocratização do país, após o período da ditadura militar. Os personagens inseridos no conto apresentam os conflitos internos, as contradições e as tensões inerentes às pessoas que frequentam esses ambientes.

No conto analisado, demonstram-se os conflitos de personagens pertencentes às classes sociais menos favorecidas, que possuem escassas expectativas de crescimento pessoal e profissional. Pelo cotidiano desses personagens, notam-se os conflitos internos, as tensões e as contradições que os negros enfrentam na cidade de São Paulo. Esses contornos tornam-se evidentes na 
exposição dos personagens em centros de ativismo social. O próprio negro brasileiro não se entende com as pessoas da agremiação negra. A desunião de alguns dos personagens do conto destacado reflete a condição dos negros na sociedade brasileira que, embora pertencentes à mesma agremiação negra, possuem sérias divergências.

\section{Referências bibliográficas}

BENJAMIN, Walter. Teses sobre o conceito de história. In:_. Magia e técnica, arte e política: ensaios sobre literatura e história da cultura. São Paulo: Brasiliense, 1987.

CANDIDO, Antonio. Literatura e sociedade. Rio de Janeiro: Ouro sobre Azul, 2006.

CUTI [Luiz Silva]. Quizila. São Paulo: Quilombhoje, 1987.

DUARTE, Eduardo Assis. Literatura e Afro-descendência. Literafro, Belo Horizonte, fev. 2019. Seção Artigos Teórico-conceituais. Disponível em: <http://www.letras.ufmg.br /literafro/artigos/artigos-teorico-conceituais/150-eduardo-de-assis-duarte-literatura -e-afrodescendencia>. Acesso em 13 abr. 2019.

HOUAISS, Antônio. Dicionário Houaiss de Língua Portuguesa. Rio de Janeiro: Objetiva, 2001.

NASCIMENTO, Abdias. Quilombismo. Petrópolis: Editora Vozes, 1980.

PEREIRA, Edimilson de Almeida. Negociação e conflito na construção das poéticas brasileiras contemporâneas. Estudos de Literatura Brasileira Contemporânea, Rio de Janeiro, n. 31, 2008, p. 25-52. Disponível em: <http://periodicos.unb.br/index.php/ estudos/article/view/2018/1591>. Acesso em: 8 abr. 2019. 
Recebido em 09/03/2019

Aceito em 29/07/2019 